\title{
Antitumor effects of the investigational selective MEK inhibitor TAK733 against cutaneous and uveal melanoma cell lines
}

\author{
Erika von Euw ${ }^{1}$, Mohammad Atefi ${ }^{\dagger}$, Narsis Attar ${ }^{1}$, Connie Chu', Sybil Zachariah, Barry L Burgess ${ }^{2}$, Stephen Mok', \\ Charles Ng${ }^{1}$, Deborah JL Wong ${ }^{1}$, Bartosz Chmielowski ${ }^{1}$, David I Lichter ${ }^{5}$, Richard C Koya ${ }^{3}$, Tara A McCannel ${ }^{2,4}$, \\ Elena Izmailova ${ }^{5}$ and Antoni Ribas ${ }^{1,3,4,6^{*}}$
}

\begin{abstract}
Background: TAK733 is a novel allosteric, non-ATP-binding, inhibitor of the BRAF substrates MEK-1/2.

Methods: The growth inhibitory effects of TAK733 were assessed in a panel of 27 cutaneous and five uveal melanoma cell lines genotyped for driver oncogenic mutations. Flow cytometry, Western blots and metabolic tracer uptake assays were used to characterize the changes induced by exposure to TAK733.

Results: Fourteen cutaneous melanoma cell lines with different driver mutations were sensitive to the antiproliferative effects of TAK733, with a higher proportion of $B R A F^{V 600 E}$ mutant cell lines being highly sensitive with IC50s below $1 \mathrm{nM}$. The five uveal melanoma cell lines had GNAQ or GNA11 mutations and were either moderately or highly sensitive to TAK733. The tested cell lines wild type for NRAS, BRAF, GNAQ and GNA11 driver mutations were moderately to highly resistant to TAK733. TAK733 led to a decrease in pERK and G1 arrest in most of these melanoma cell lines regardless of their origin, driver oncogenic mutations and in vitro sensitivity to TAK733. MEK inhibition resulted in increase in pMEK more prominently in NRAS ${ }^{\mathrm{Q} 1 L}$ mutant and GNAQ mutant cell lines than in BRAF ${ }^{V 600 E}$ mutant cell lines. Uptake of the metabolic tracers FDG and FLT was inhibited by TAK733 in a manner that closely paralleled the in vitro sensitivity assays.

Conclusions: The MEK inhibitor TAK733 has antitumor properties in melanoma cell lines with different oncogenic mutations and these effects could be detectable by differential metabolic tracer uptake.
\end{abstract}

Keywords: Melanoma, MEK inhibitor, BRAF mutation, Oncogenes, MAPK signaling

\section{Introduction}

Most melanomas have mutually-exclusive activating mutations in the mitogen-activated protein kinase (MAPK) pathway involving NRAS or BRAF genes in melanomas of skin primary, $c$-Kit in acral and mucosal melanomas, and GNAQ and GNA11 in uveal melanomas [1-5]. These mutations render melanoma cells independent of the normal receptor tyrosine kinase (RTK)-mediated pathway regulation, and constitutively drive melanoma cells to oncogenic proliferation and survival [6]. The most common of these mutations

\footnotetext{
*Correspondence: aribas@mednet.ucla.edu

${ }^{\dagger}$ Equal contributors

'Department of Medicine, Division of Hematology/Oncology, University of California Los Angeles (UCLA), Los Angeles, CA, USA

${ }^{3}$ Jonsson Comprehensive Cancer Center at UCLA, Los Angeles, CA, USA

Full list of author information is available at the end of the article
}

is the $B R A F^{V 600 E}$ mutation, present in approximately $50 \%$ of melanomas of skin origin. $B R A F^{V 600 E}$ mutant cutaneous melanomas are dependent on MAPK signaling for cellcycle progression and proliferation, and have high sensitivity to type I BRAF inhibitors and to MEK inhibitors [7-10]. Very high response rates and improved survival have been noted with the administration of the type I BRAF inhibitor vemurafenib (formerly PLX4032/RG7204) to patients with $\mathrm{BRAF}^{\mathrm{V} 600 \mathrm{E}}$ mutant cutaneous metastatic melanoma [11-13]. Tumor responses were dependent on the presence of the $B R A F^{V 600 E}$ oncogene and efficient inhibition of the MAPK pathway as detected by decreased phosphorylation of ERK [8]. Inhibition of the immediately downstream MEK1/2 kinases in BRAF ${ }^{\mathrm{V} 600 \mathrm{E}}$ mutant cutaneous melanoma was shown to lead to marked inhibition of 
cell proliferation in cell lines [7]. The attractiveness of inhibiting at the level of MEK is supported by the very high kinase specificity of allosteric MEK inhibitors and the fact that MEK1/2 kinases are critically positioned as a funnel in the MAPK pathway downstream of the three RAS isoforms and the three RAF isoforms. Therefore, the inhibition of MEK1/2 with specific MEK inhibitors may result in blocking MAPK signaling from multiple upstream oncogenes. Preclinical studies suggest that some NRAS-mutant cutaneous melanomas may also exhibit sensitivity to RAF or MEK inhibition [14], whereas KRAS mutations have conferred only marginal sensitivity [15]. Gene expression profiling studies mapping the gene signatures downstream of a constitutively activated MAPK pathway suggested that cutaneous melanoma cell lines with NRAS mutations are less dependent in signaling through this pathway compared to $B R A F^{V 600 E}$ mutant cutaneous melanoma cell lines $[10,16]$, explaining in part the differential sensitivity of NRAS and BRAF mutant cells to MEK inhibitors [7].

$B R A F$ and NRAS mutations are absent in melanomas arising in the uveal layer of the eye, but mutually exclusive somatic mutations in the heterotrimeric $G$ protein alphasubunit, GNAQ, or in GNA11, are present in the great majority of uveal melanomas [4,5]. It had long been noted that uveal melanomas have constitutive MAPK signaling $[17,18]$, and it is now understood that it is because of the presence of GNAQ or GNA11 mutations. These mutations occur in codons 183 or 209 in the Ras-like domain and result in constitutive activation, turning the GNA proteins into dominant-acting oncogenes signaling through the MAPK pathway [4]. GNAQ knockdown, as well as treatment with the U0126 MEK inhibitor, resulted in inhibition of MAPK signaling and loss of viability [4]. Therefore, MEK inhibition may be a way to treat metastatic melanoma of uveal origin, a disease that has been highly refractory to most therapies tested to date.

TAK733 represents a novel and distinct inhibitor of MEK that is capable of allosteric inhibition of the RAF substrates MEK-1 and MEK-2 [19]. This compound has been characterized extensively and shown to possess desirable drug-like attributes [20]. In the current studies we have analyzed the sensitivity and resistance of human cutaneous and uveal melanoma cell lines to this novel MEK inhibitor, with analysis of the oncogenic driver mutations and downstream signaling alterations and functional effects.

\section{Results}

\section{Sensitivity of cutaneous and uveal melanoma cell lines to} TAK733

Cutaneous and uveal melanoma cell lines were cultured in vitro in the presence of increasing concentrations of TAK-733 for 72 hours to determine the half maximal inhibitory concentration (IC50) in cell proliferation assays. Cell lines with an IC50 less than $10 \mathrm{nM}$ were considered sensitive, and cell lines with IC50 less than 1 nM were considered highly sensitive. Among 12 $B R A F^{V 600 E}$ mutated cutaneous cell lines tested, seven were highly sensitive to TAK-733 with IC50s less than 1 nM (Figure 1 and Additional file 1: Figure S1). Five $B R A F^{V 600 E}$ mutant cutaneous cell lines had an IC50 higher than $100 \mathrm{nM}$ and were considered highly resistant to this agent.. Among ten NRAS ${ }^{\mathrm{Q} 61}$ mutant cutaneous melanoma cell lines, four were sensitive with IC50s below $10 \mathrm{nM}$, but none was highly sensitive. Our panel also included five cutaneous melanoma cell lines wild type for mutations in NRAS, BRAF, GNAQ and GNA11 and only one was highly sensitive to TAK733 with IC50s below $1 \mathrm{nM}$, while two were considered sensitive with IC50 less than $10 \mathrm{nM}$. All five uveal melanoma cell lines were sensitive to TAK733 with IC50 values below $10 \mathrm{nM}$, with three of them being highly sensitive. All these cell lines carried GNAQ or GNA11 driver mutations (Figure 1 and Table 1). Overall, there was a clear trend of higher sensitivity in BRAF mutant cell lines, but all subgroups included cell lines with variable sensitivity and also high resistance to exposure to the MEK inhibitor.

\section{TAK733 has similar inhibitory effects on cell cycle in} sensitive and resistant cutaneous melanoma cell lines To study the effects of TAK733 on cell cycle progression downstream of MEK signaling we used DAPI flow cytometric staining (representative examples of flow histograms in Figure 2a and b). For these studies we chose two NRAS mutants and four BRAF mutants that represented the spectrum of sensitivities of these cell lines. The NRAS mutants M207 (sensitive) and M244 (highly resistant) both had a dose-dependent G1 arrest with increasing concentrations of TAK733 (Figure 2c). The same was evident with the four BRAF mutants, including the two with high sensitivity (M229 and M249) and the highly resistant (M233 and M263). The sub-G1 peak also did not predict the cell proliferation assay results, even though the sharpest increase was in M249, one of the most sensitive cell lines (Figure 2 a and c). Overall, TAK733 exposure for up to 48 hours led to a similar G1 arrest in melanoma cell lines regardless of their origin, driver oncogenic mutations and in vitro sensitivity to TAK733).

\section{Modulation of MAPK and PI3k/akt signaling pathways upon exposure to TAK733}

To explore how cell lines with different mutations respond differently to TAK733 we analyzed signaling pathways in representative cell lines with similar growth kinetics but with markedly different sensitivities to 


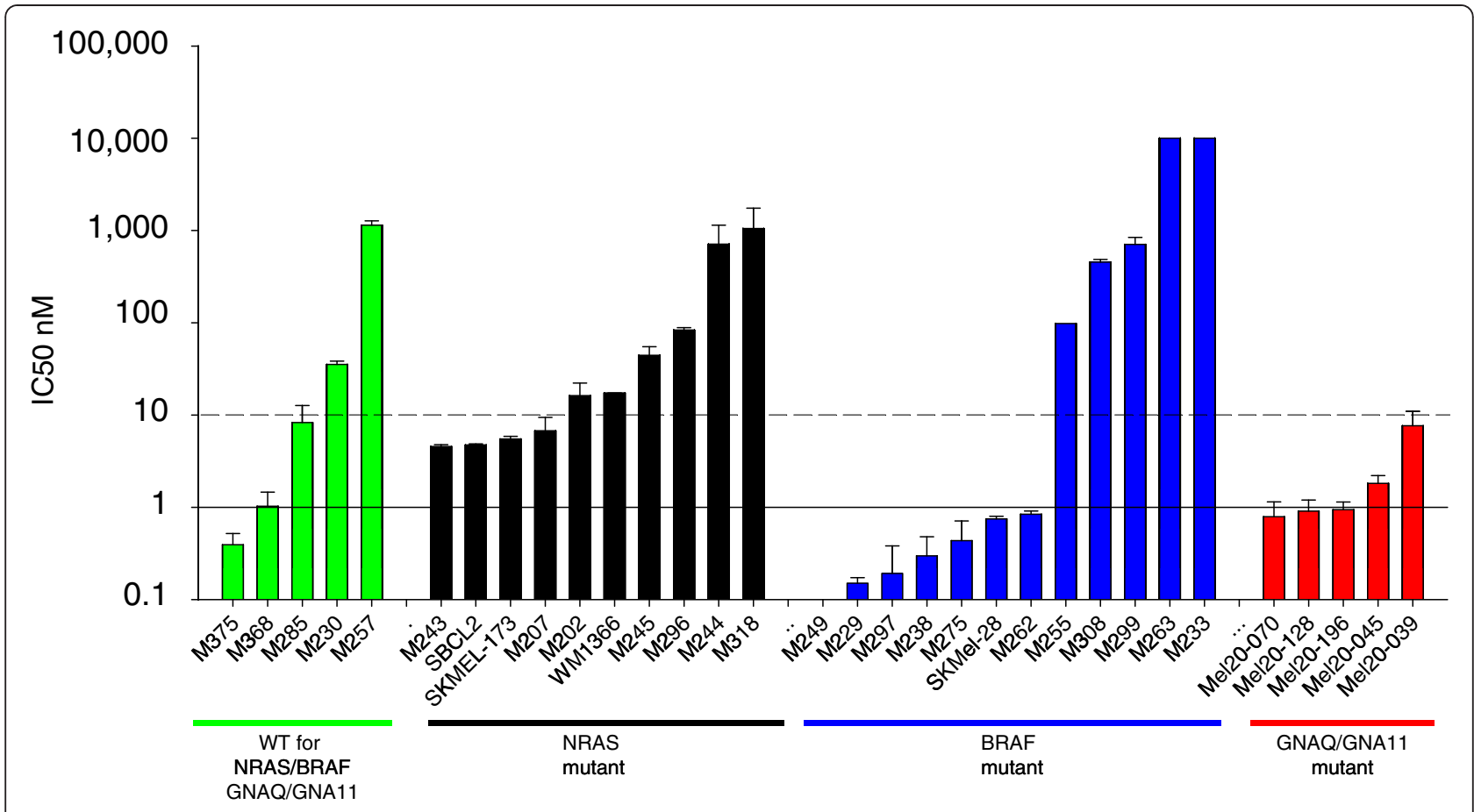

Figure 1 TAK733 half maximal inhibition concentration (IC50) values as a function of BRAF, NRAS, GNAQ or GNA11 mutational status. The cells were treated for 72 hours and cell viability was determined by MTS colorimetric assay. IC50 values ( $\mathrm{x}$-axis) are expressed in nM for TAK733. Error bars represent standard error of the mean.

TAK733. Among the NRAS $S^{\text {61L }}$ mutant cutaneous group we chose the resistant M244 and the sensitive M207. Among the $B R A F^{V 600 E}$ mutant cutaneous group we chose M229 and M249 as representatives of highly sensitive cutaneous cell lines, and M233 and M263 as resistant cutaneous cell lines. In our panel, all the uveal melanoma cell lines were sensitive to TAK733 and we picked three as representative samples with GNAQ mutations. As expected based on prior data [21], MEK inhibition resulted in increase of PMEK in non$B R A F^{V 600 E}$ mutant cell lines (Figure 3). This was more prominent in $N R A S^{\mathrm{Q} 61 L}$ mutant and uveal melanoma cell lines than in $B R A F^{V 600 E}$ mutant cell lines, which had a higher baseline level of pMEK. In all cases, TAK733 induced a marked dose-dependent decrease of pERK, regardless of the driver oncogenic mutation or the sensitivity or resistance to this agent in cell viability assays. On the contrary, effects on pAKT and pS6K varied according to the cell origin, oncogenic events and sensitivity to TAK733. BRAF $F^{V 600 E}$ mutant cell lines resistant to TAK733 showed no inhibition of pAKT or pS6K, while there was a general trend towards inhibition of these two phosphorylated molecules in sensitive cell lines. Of note, in the uveal melanoma cell lines and in the cutaneous melanoma cell line M229, the baseline level of pAKT was undetectable by Western blot, so no inhibition could be recorded in them. Changes in pS6 tended to follow changes in pS6K in the cutaneous melanoma cell lines but not in the uveal melanoma cell lines. In a timecourse analysis of signaling events upon exposure to TAK733, both the sensitive M229 and the resistant M233 cell lines with $B R A F^{V 600 E}$ mutations showed initial inhibition of pERK, but the resistant cell line recovered pERK signaling with time (Additional file 2: Figure S2). This different time-course effect was not evident for the inhibition of pAKT or pS6K in the resistant cell line, while they were permanently inhibited over the 48 hour study period in the sensitive cell line.

\section{Differential metabolic tracer uptake between cell lines sensitive and resistant to TAK733}

We explored the use of metabolic tracers to differentiate response or resistance to TAK733 in six cutaneous melanoma cell lines with the goal of a future use of these tracers in PET scanning studies in the clinic. Thymidine is taken up by proliferating cells and the PET tracer $\left[{ }^{18} \mathrm{~F}\right] \mathrm{FLT}$ can be used in patients. Consistent with the cell cycle analysis data, all the tested cell lines had some degree of inhibition of tritium-labeled thymidine $\left({ }^{3} \mathrm{H}\right.$ thymidine) uptake upon exposure to TAK733 regardless of their sensitivity in vitro. The highest levels of inhibition were in the highly sensitive $B R A F^{V 600 E}$ mutant cell lines 
Table 1 Characterization of oncogenic alterations in melanoma cell lines tested for sensitivity to TAK733

\begin{tabular}{|c|c|c|}
\hline $\begin{array}{l}\text { Driver Oncogenic } \\
\text { Mutation }\end{array}$ & Cell Line & $\begin{array}{l}\text { Known Oncogenic } \\
\text { Alterations }\end{array}$ \\
\hline \multirow{6}{*}{$\begin{array}{l}\text { Wild type for BRAF } \\
\text { and NRAS }\end{array}$} & M230 & KIT L576P \\
\hline & M257 & CDKN2A R80 \\
\hline & & BRAF amplification \\
\hline & M285 & None detected \\
\hline & M368 & None detected \\
\hline & M375 & None detected \\
\hline \multirow[t]{18}{*}{ NRAS Mutants } & M202 & NRAS ${ }^{Q 61 L}$ \\
\hline & & EGFR amplification \\
\hline & & CDKN2A homozygous deletion \\
\hline & M207 & NRAS ${ }^{Q 61 L}$ \\
\hline & & MITF amplification \\
\hline & & EGFR L747_P753 >S \\
\hline & & PTEN heterozygous deletion \\
\hline & M243 & NRAS $S^{\mathrm{Q} 61 \mathrm{H}}$ homozygous \\
\hline & & PTEN ${ }^{E 156 G}$ heterozygous \\
\hline & & CTNNB1_D32Y \\
\hline & M245 & NRAS ${ }^{\mathrm{Q} 61 \mathrm{~K}}$ heterozygous \\
\hline & & $\operatorname{TP} 53^{R 273 H}$ \\
\hline & M244 & NRAS ${ }^{\mathrm{Q61K}}$ heterozygous \\
\hline & M296 & $N R A S^{Q 61 R}$ heterozygous \\
\hline & M318 & NRAS ${ }^{\mathrm{Q} 61 \mathrm{~L}}$ heterozygous \\
\hline & & PIK3CA ${ }^{C 420 R}$ \\
\hline & $\mathrm{SBCL2}$ & NRAS $S^{\mathrm{Q} 11 \mathrm{~K}}$ homozygous \\
\hline & Wn1366 & NRAS ${ }^{\mathrm{Q} 61 \mathrm{~L}}$ heterozygous \\
\hline \multirow[t]{19}{*}{ BRAF mutants } & M229 & $B R A F^{\mathrm{V} 600 \mathrm{E}}$ homozygous \\
\hline & & BRAF amplification \\
\hline & & MITF amplification \\
\hline & & AKT1 amplification \\
\hline & & PTEN heterozygous deletion \\
\hline & M233 & $B R A F^{V 600 E}$ heterozygous \\
\hline & & BRAF amplification \\
\hline & & AKT1 amplification \\
\hline & & CCND1 amplification \\
\hline & & EGFR amplification \\
\hline & & CDKN2A homozygous deletion \\
\hline & & PTEN homozygous deletion \\
\hline & M238 & BRAF $^{V 600 E}$ heterozygous $^{1}$ \\
\hline & & CDKN2A homozygous deletion \\
\hline & & PTEN heterozygous deletion \\
\hline & M249 & $B R A F^{V 600 E}$ heterozygous \\
\hline & & BRAF amplification \\
\hline & & MITF amplification \\
\hline & & AKT2 amplification \\
\hline
\end{tabular}

Table 1 Characterization of oncogenic alterations in melanoma cell lines tested for sensitivity to TAK733 (Continued)

\begin{tabular}{|c|c|c|}
\hline & \multirow{3}{*}{ M255 } & PTEN homozygous deletion \\
\hline & & $B R A F^{V 600 E}$ heterozygous \\
\hline & & AKT2 amplification \\
\hline & \multirow{7}{*}{ M262 } & CCND1 amplification \\
\hline & & EGFR amplification \\
\hline & & CDKN2A homozygous deletion \\
\hline & & $B R A F^{V 600 E}$ homozygous \\
\hline & & AKT1 E17K \\
\hline & & AKT1 amplification \\
\hline & & EGFR amplification \\
\hline & \multirow{3}{*}{ M263 } & CDKN2A homozygous deletion \\
\hline & & $B R A F^{V 600 E}$ heterozygous \\
\hline & & CDKN2A heterozygous deletion \\
\hline & M275 & $B R A F^{V 600 E}$ heterozygous \\
\hline & \multirow[t]{2}{*}{ M297 } & $B R A F^{V 600 E}$ homozygous \\
\hline & & PTEN ${ }^{G 165 X}$ homozygous \\
\hline & M299 & $B R A F^{V 600 E}$ heterozygous \\
\hline & \multirow[t]{6}{*}{ M308 } & $B R A F^{V 600 E}$ heterozygous \\
\hline & & BRAF amplification \\
\hline & & MITF amplification \\
\hline & & AKT2 amplification \\
\hline & & EGFR amplification \\
\hline & & CDKN2A heterozygous deletion \\
\hline & \multirow[t]{6}{*}{ SKmel28 } & $B R A F^{V 600 E}$ homozygous \\
\hline & & $E G F R^{P 753 S}$ \\
\hline & & MITF amplification \\
\hline & & CCND1 amplification \\
\hline & & CDKN2A heterozygous deletion \\
\hline & & PTEN heterozygous deletion \\
\hline \multirow[t]{5}{*}{ GNAQ or GNA11 } & Mel20-06-039 & GNAQQ209L heterozygous \\
\hline & Mel20-06-045 & GNAQ Q209P heterozygous \\
\hline & Mel20-07-070 & GNA11 ${ }^{\text {Q209L }}$ heterozygous \\
\hline & Mel20-08-128 & GNA11 ${ }^{\text {Q209L }}$ heterozygous \\
\hline & Mel20-09-196 & GNAQQ209P heterozygous \\
\hline
\end{tabular}

Legend: ${ }^{1}$ Tandem mutation where the codon changed from GTG to GAA.

M229 and M249 and the relatively resistant M263 cell line (Figure 4a). Changes in uptake of tritium-labeled 2'-deoxyD-glucose $\left({ }^{3} \mathrm{H}-2 \mathrm{DDG}\right)$ were analyzed to study effects of TAK733 on PET scans with the commonly used PET tracer $\left[{ }^{18} \mathrm{~F}\right]$ FDG. The lowest degree of inhibition was in the two most resistant cell lines, the $B R A F^{V 600 E}$ mutant M233 and the NRAS ${ }^{\mathrm{Q} 61 K}$ mutant M244 (Figure 4b). Therefore, changes in the uptake of the ${ }^{3} \mathrm{H}-2 \mathrm{DDG}$ metabolic tracer most closely followed the results of the cell viability assays. 
a)

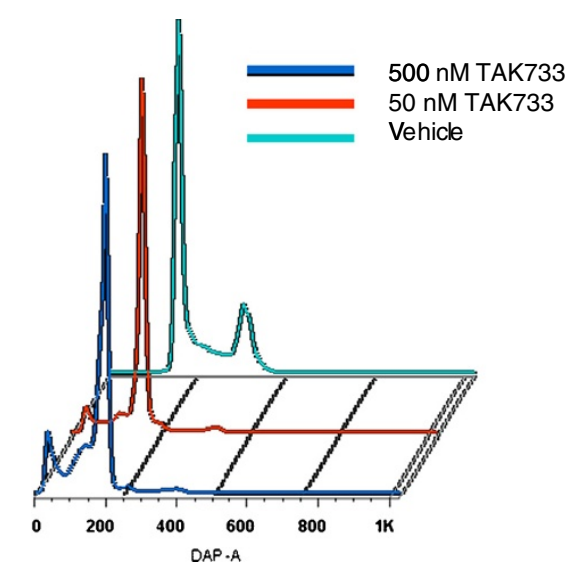

M249 (BRAF mutant, sensitive)

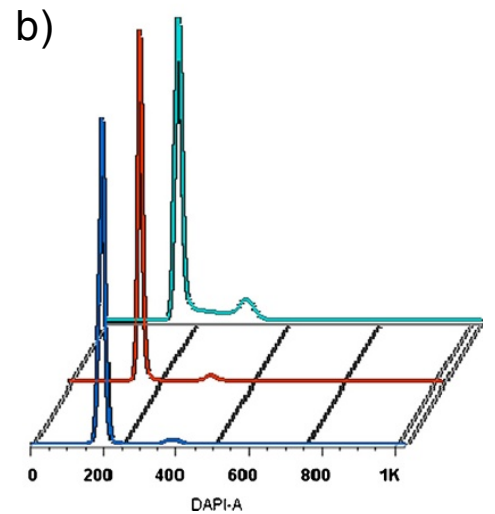

M233 (BRAF mutant, resistant)

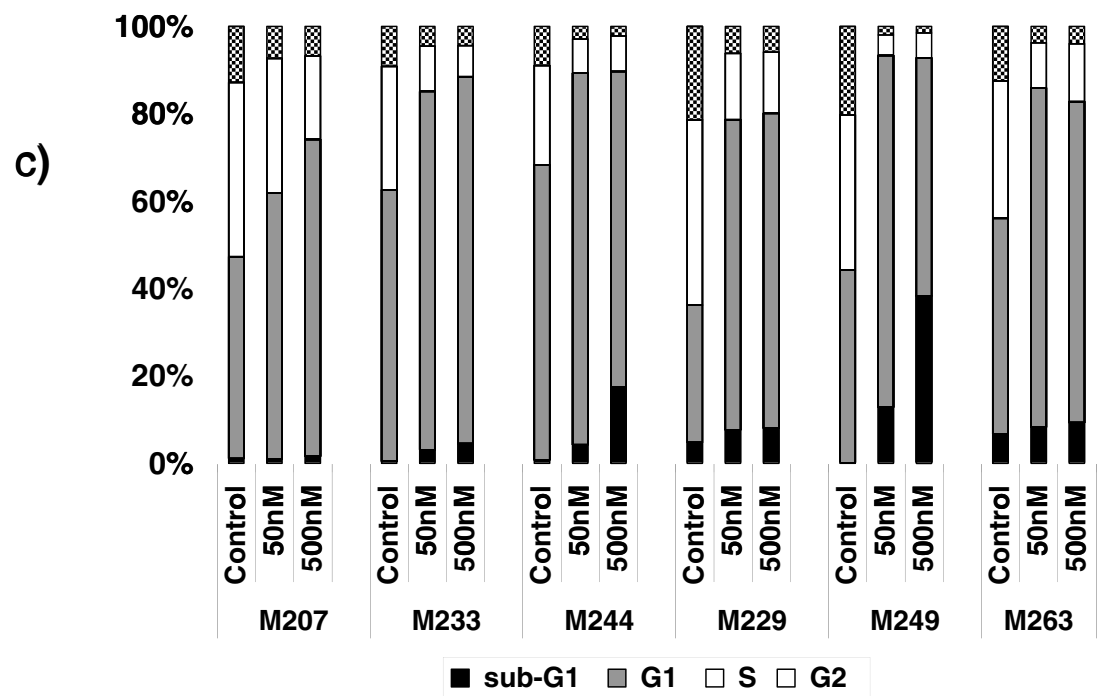

Figure 2 Effects of TAK733 on cell cycle. $\mathbf{a}$ and $\mathbf{b}$ ) Examples of the flow histograms of a sensitive and a resistant cutaneous melanoma cell line. c) Bar graph of G1, S and G2 phase as percent change from baseline. Six melanoma cell lines representative of the spectrum of sensitivities of NRAS mutants (sensitive: M207; resistant: M244) and BRAF mutants (sensitive: M229 and M249; resistant: M233 and M263) were cultured with 50 $\mathrm{nM}$ and $500 \mathrm{nM}$ of TAK733 for 48 hours and stained with DAPI for cell cycle analysis.

\section{Discussion}

Initial data testing MEK inhibitors in melanoma cell lines suggested a high level and selective sensitivity in $B R A F^{V G O O E}$ mutant melanoma cell lines, with low sensitivity in melanoma cell lines with other driver oncogenes [7]. Further testing with expanded panels of cell lines has confirmed a trend towards higher sensitivity in $B R A F^{V 600 E}$ mutant melanoma, but has also provided evidence that some melanoma cell lines with NRAS activating mutations are sensitive to MEK inhibitors $[10,14]$. The higher sensitivity of $B R A F$ mutant cell lines compared to NRAS mutant cell lines is generally represented in our series, but some $B R A F$ mutants have high resistance to the MEK inhibitor while some NRAS mutants are sensitive. It is certainly possible that our $B R A F^{V 600 E}$ mutant cutaneous melanoma panel is skewed for cell lines with natural resistance to inhibition of the MAPK pathway, since we have previously reported a similar greater than expected frequency of cutaneous cell lines resistant to the type I BRAF inhibitor vemurafenib $[9,22]$. The molecular basis for this relative high frequency of natural resistance of $B R A F^{V 600 E}$ mutant cutaneous melanoma cell lines in our series is currently not well understood. Initial exploration of secondary oncogenic events in the PI3K/AKT pathway (such as PTEN deletions) did not clearly differentiate naturally sensitive and resistant $B R A F^{V 600 E}$ mutant cutaneous melanomas to the BRAF inhibitor vemurafenib, but downstream signaling 


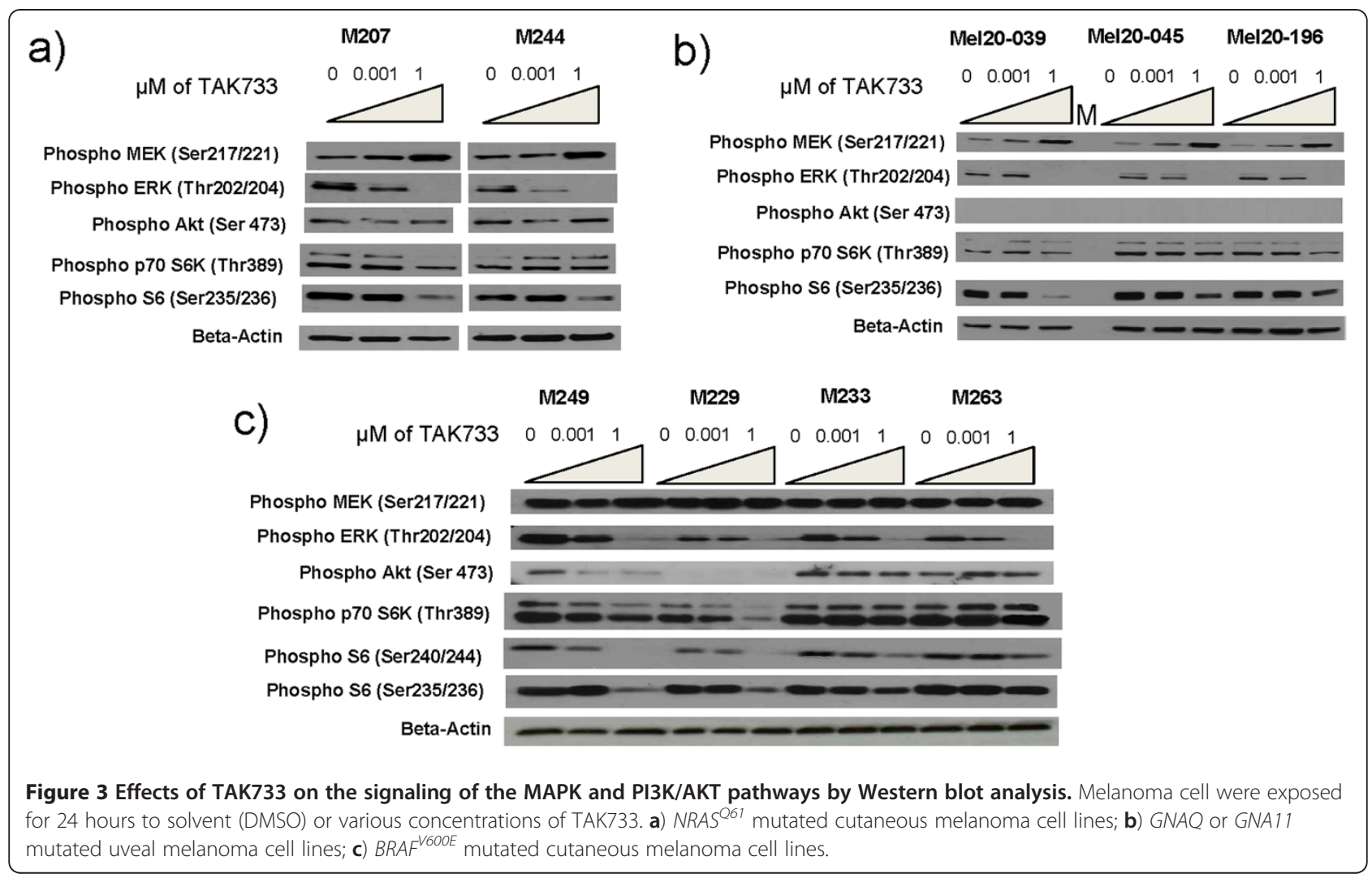

studies did suggest that the PI3K/AKT pathway may be involved $[9,22]$. In the current studies we noted the same phenomenon, a lack of correlation between natural sensitivity and resistance to TAK733 based solely on oncogenic analysis of the cell lines using SNP arrays or targeted oncogene sequencing for mutations frequently present in cancer. However, there was a suggestion from Western blot analyses of signaling pathways that differential effects of MEK inhibitor altering signaling through the PI3K/AKT pathway may be related to resistance. This observation may provide means to explore combinations of MEK inhibitors with PI3K or AKT inhibitors that may be useful in NRAS or BRAF mutant melanomas, which could be due to hyperactive receptor tyrosine kinase signaling leading to resistance [22-24].

BRAF has only MEK as a substrate for activation [6], and as discussed cutaneous cell lines with the $B R A F^{V 600 E}$ mutation frequently have high sensitivity to MEK inhibitors in vitro [7]. However, patients with $B R A F^{V 600 E}$ mutant cutaneous metastatic melanoma enrolled in clinical trials testing MEK inhibitors $[25,26]$ have lower response rates than the use of the type I BRAF inhibitors vemurafenib or dabrafenib (GSK2118436) in the same population [11,13,27]. The reason for this discrepancy between in vitro and in vivo results with MEK inhibitors is not clearly understood at this time, but it may be related to a lower therapeutic window of MEK inhibitors in the clinic compared to type I BRAF inhibitors. This could be explained by the paradoxical activation of the MAPK pathway in $B R A F$ wild type cutaneous cells, where type I BRAF inhibitors increase (or do not change) MAPK signaling in normal cells, while they efficiently block the MAPK pathway downstream of oncogenic BRAF ${ }^{\mathrm{V} 600}$. On the contrary, MEK inhibitors can equally block the MAPK pathway downstream of both oncogenic and wild type BRAF. This lack of differentiation most likely causes the dose limiting toxicities (DLT) at exposures in vivo that do not adequately block the MAPK pathway in $B R A F^{V 600}$ mutant melanoma. Despite this, MEK inhibitors are likely to have a role in the treatment of cancers with constitutive MAPK signaling from oncogenic mutations upstream of MEK. In particular the combination of MEK and RAF inhibitors may be beneficial by inducing higher MAPK inhibition in mutant cells and therefore lowering the cancer escape mechanisms and also decreasing toxicities from paradoxical MAPK activation [28], such as the development of cutaneous squamous cell carcinomas [29].

The majority of uveal melanomas bear a mutually exclusive activating mutation in either GNAQ or GNA11, resulting in overlapping functions in melanoma cells with the constitutive upregulation of the MAPK pathway [5]. In preclinical models it was shown that at least 


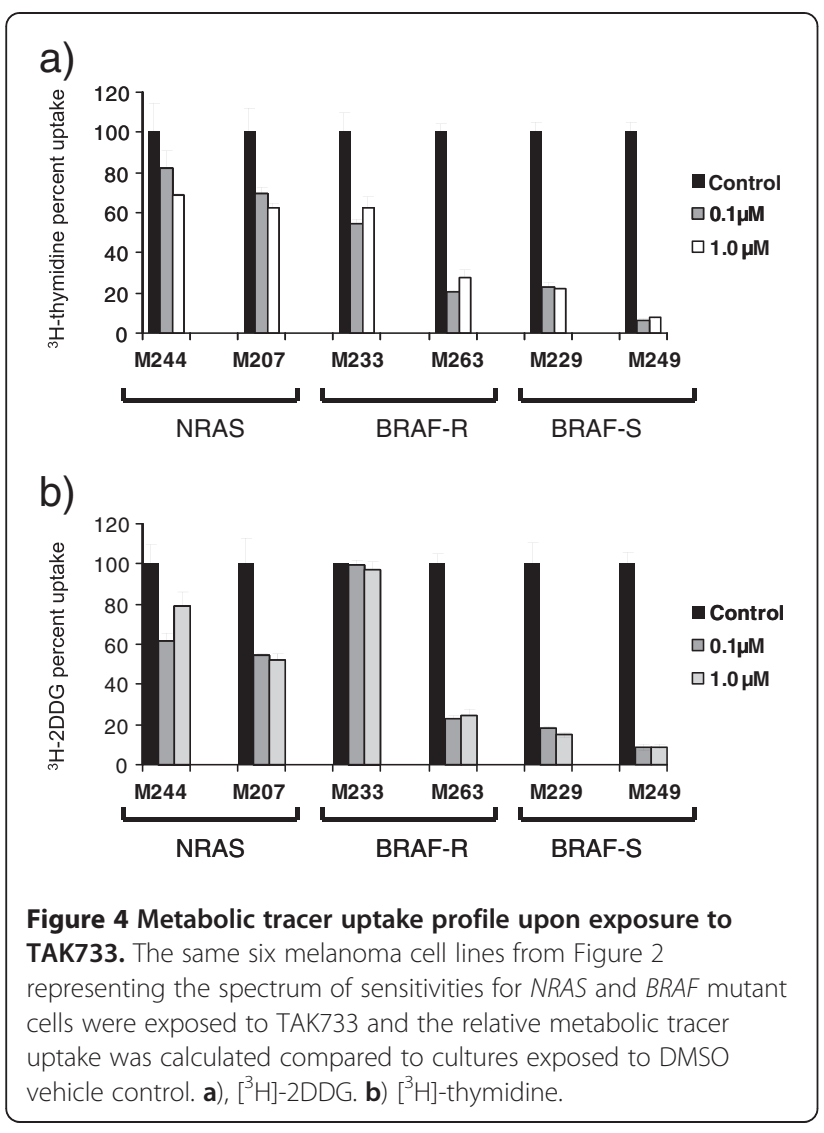

the GNAQ mutation resulted in sensitivity to downstream blocking of the MAPK pathway with a MEK inhibitor [4]. Our data demonstrating the sensitivity of uveal melanoma cell lines to TAK733 provides further evidence that it may be a clinical strategy to use MEK inhibitors to treat metastatic uveal melanomas. However, the same issues of a lack of correlation between the in vitro and clinical results when blocking oncogenic MAPK signaling using MEK inhibitors may apply to uveal melanomas.

The differential uptake of ${ }^{3} \mathrm{H}$-radiolabeled compounds that are trapped intracellularly upon metabolic processing allows testing their potential future use as PET probes in the clinical development of a new agent. It is anticipated that these radiolabeled metabolic probes can provide non-invasive pharmacodynamic information with the use of clinical PET scanners. In our studies, the highly sensitive cell lines had a decrease in the uptake of radiolabeled thymidine and deoxy-glucose that seemingly correlated with the cell viability and cell cycle results. However, there were variable changes in the highly resistant cell lines that did not directly correlate with the cell viability assay results (ex. M263 with marked decrease in the uptake of both tracers despite its resistance to TAK733). The metabolic tracer uptake studies were performed at a slightly earlier time point than the proliferation/viability assays to capture earlier events, and may be the reason of the discrepancy in results. These results raise the point that earlier PET scans with these tracers to detect early pharmacodynamic changes may not fully predict the later restaging imaging CT scan results.

In conclusion, inhibition of oncogenic MAPK signaling through MEK1 and MEK2 by TAK733 results in antitumor activity in vitro against a large subset of melanoma cell lines. We confirmed the previously reported cytotoxic effect of a MEK inhibitor against cell lines with $B R A F^{V 600 E}$ mutations, but in addition the cytotoxic activity was evident in a high proportion of melanoma cell lines with NRAS, GNAQ or GNA11 driver mutations. The antiproliferative and cell metabolism effects of this MEK inhibitor against melanoma cell lines can be detected with metabolic probes that could be tested with caution in the clinical development of this agent using PET imaging.

\section{Material and methods}

\section{Reagents and cell lines}

TAK-733 was obtained under a materials transfer agreement (MTA) from Millennium Pharmaceuticals, Inc. (Cambridge, MA) and dissolved in dimethyl sulfoxide (DMSO, Fisher Scientific, Morristown, NJ) to a stock concentration of $10 \mathrm{mM}$. The cutaneous melanoma cell lines of the $\mathrm{M}$ series were established from biopsies of metastatic melanoma of cutaneous origin as previously described [9] under the UCLA IRB approval \#02-08-067 following the Declaration of Helsinki. SKMEL28, Wn1366 and SBCL2 were obtained from the American Type Culture Collection (ATCC, Rockville, MD). The uveal melanoma cell lines of the Mel20 series were established from fine needle aspirates of primary uveal melanoma lesions or from a metastatic uveal melanoma lesion (Mel20-09-196), obtained under the UCLA IRB approval \#04-12-084. In the case of uveal melanoma cell lines, cells were cultured in DMEM with L-glutamine and $4.5 \mathrm{~g}$ /liter glucose (Mediatech Inc., Manassas, VA) containing 10\% (unless noted, all percentages represent volume to volume) fetal bovine serum (FBS, Invitrogen, Carlsbad, CA) and 1\% penicillin, streptomycin and amphotericin (Omega Scientific), with the addition of $5 \mu \mathrm{g} / \mathrm{ml}$ of bovine insulin (Sigma-Aldrich, St. Louis, MO). All cell lines were mycoplasma free when periodically tested using a Mycoalert assay (Lonza, Rockland, ME).

\section{Oncogenic analysis of cell lines}

Cell lines were analyzed for known oncogenic activating mutations and deletions using multiplex PCR as well as by MALDI-TOF mass spectrometry (Sequenom, San Diego, CA) [30]. Point mutations were confirmed by PCR and direct sequencing as previously described [9]. In addition, most cell lines were analyzed by SNP arrays with DNA extracted from the cell lines hybridized onto 
Illumina Beadchip Human Exon 510 S-Duo (Illumina Inc., San Diego, CA).

\section{Cell proliferation and viability assays}

Melanoma cell lines were treated with TAK-733 or parallel DMSO vehicle control at the given concentrations for 72 hours. Cell viability was measured using a tetrazolium compound [3-(4,5-dimethylthiazol-2-yl)-5- (3-carboxymethoxyphenyl)-2-(4-sulfophenyl)-2 H-tetrazolium (MTS)based colorimetric cell proliferation assay (Promega, Madison, WI) as previously described [9].

\section{Cell cycle analysis}

Cells were treated with different concentrations of TAK733 (50 and $500 \mathrm{nM}$ ) or parallel vehicle control for 48 hours, fixed by Cytofix/Cytoperm solution and washed by Perm/Wash buffer according to fixation and pereabilization method recommended by $\mathrm{BD}$ bioscience, and then stained in sterile PBS containing 1.0\% albumin bovine serum, $0.1 \%$ Nonidet P-40 (Sigma-Aldrich) and $3 \mu \mathrm{M}$ DAPI (4',6-diamidino-2-phenylindole). Flow cytometry was analyzed using FlowJo (Tree Star Inc, Asland, OR).

\section{Western blotting}

Western blotting was performed as previously described [31]. Primary antibodies included pAkt (Ser473), pAkt (Thr308), Akt, pS6K (Thr389), S6K, pS6 (Ser235/236), S6, pMEK (Ser217/221), MEK, pERK1/2 (Thr204/205), and ERK (all from Cell Signaling Technology, Danvers, MA), and $\alpha$-actin (Sigma-Aldrich). Immunoreactivity was revealed using the ECL kit (Amersham Biosciences Co, Piscataway, NJ).

\section{In vitro metabolic tracer uptake assay}

$3 \times 10^{4}$ cells/well were plated on $0.001 \%$ poly-L-lysine (Sigma-Aldrich) pre-incubated filter bottom 96-well plates (multiscreen HTS GV $0.22 \mu \mathrm{m}$ opaque, Millipore, Billerica, MA) and rested for 24 hours. 0.1 and $1 \mu \mathrm{M}$ of TAK733 or parallel DMSO vehicle control were added in triplicate for 20 hours. Cells were incubated for 1 hour with $2.0 \mu \mathrm{Ci}$ with metabolic tracers chosen as analogues of PET tracers: ${ }^{3} \mathrm{H}-\mathrm{DDG}$ (American Radiolabeled Chemicals Inc., St. Louis, MO) in glucose-free RPMI 1640 (Invitrogen), or methyl- ${ }^{3} \mathrm{H}$-thymidine (thymidine, Moravek Biochemicals Inc., Brea, CA) in RPMI 1640. Extracellular metabolic tracer was washed off using a multiscreen HTS vacuum manifold system (Millipore). $100 \mu \mathrm{L}$ scintillation fluid (Perkin Elmer, Waltham, MA) was added to each well and tritium count was measured on a 1450 microbeta trilux microplate (Perkin Elmer).

\section{Additional files}

Additional file 1: Figure S1 TAK733 MTS-based colorimetric cell proliferation assay curves in melanoma cell lines of cutaneous origin according to their BRAF (A) or NRAS (B) mutational status, WT (C) and of uveal origin (D). Modulation of the melanoma cell line viability at a range of different concentrations of TAK733. The effects of TAK733 on cell growth and viability were analyzed after 72 hours of treatment using an MTS assay.

Additional file 2: Figure S2 Time-course analyses of the effects of TAK733 on the signaling of the MAPK and PI3K AKT pathways by Western blot. Two BRAF VGO0E melanoma cell lines were exposed for varying time points to TAK733. A) The sensitive BRAF $F^{V 600 E}$ mutated cutaneous melanoma cell line $\mathrm{M} 229$; $\mathrm{B}$ ) The resistant $B R A F^{V 600 E}$ mutated cutaneous melanoma cell line M233.

\section{Competing interests}

Erika von Euw, Mohammad Atefi, Narsis Attar, Connie Chu, Sybil Zachariah, Barry L. Burgess, Stephen Mok, Charles Ng, Deborah J.L. Wong, Bartosz Chmielowski, Richard C. Koya, Tara A. McCannel: Have no competing interests. David I. Lichter, Elena Izmailova: Are employees of Millennium Pharmaceuticals, Inc., the manufacturer of TAK733. Antoni Ribas: Is a compensated ad hoc advisor to Millennium Pharmaceuticals, Inc., the manufacturer of TAK733.

\section{Acknowledgements}

This work was funded by The Seaver Institute, the Melanoma Research Foundation, the Melanoma Research Alliance, the Louise Belley and Richard Schnarr Fund, the Wesley Coyle Memorial Fund, the Garcia-Corsini Family Fund, the Keiter Family Foundation and the Caltech-UCLA Joint Center for Translational Medicine (all to A.R.).

\section{Author details}

1 Department of Medicine, Division of Hematology/Oncology, University of California Los Angeles (UCLA), Los Angeles, CA, USA. ²Department of Ophthalmology, The Jules Stein Eye Institute, UCLA, Los Angeles, CA, USA. 3 Jonsson Comprehensive Cancer Center at UCLA, Los Angeles, CA, USA. ${ }^{4}$ Jonsson Comprehensive Cancer Center at UCLA, Los Angeles, CA, USA. ${ }^{5}$ Millennium Pharmaceuticals, Inc., Cambridge, MA, USA. ${ }^{6}$ Division of Hematology-Oncology, 11-934 Factor Building, UCLA Medical Center, 10833 Le Conte Avenue, Los Angeles, CA 90095-1782, USA.

\section{Authors' contributions}

EE, MA, NA, CC, SZ, BLB, SM, CN, DJLW, DIL, RCK: Performed experiments. EE, MA, TAM, El, AR: Designed the studies. BLB, BC, El, AR: Provided key reagents. EE, MA, AR: Wrote the manuscript. EE, MA, NA, CC, SZ, BLB, SM, CN, DJLW, BC, DIL, RCK, TAM, El, AR: All authors approved the final manuscript.

Received: 21 August 2011 Accepted: 19 April 2012 Published: 19 April 2012

\section{References}

1. Padua RA, Barrass N, Currie GA: A novel transforming gene in a human malignant melanoma cell line. Nature 1984, 311:671-673.

2. Davies H, Bignell GR, Cox C, Stephens P, Edkins S, Clegg S, Teague J, Woffendin H, Garnett MJ, Bottomley W, et al: Mutations of the BRAF gene in human cancer. Nature 2002, 417:949-954.

3. Curtin JA, Fridlyand J, Kageshita T, Patel HN, Busam KJ, Kutzner H, Cho KH, Aiba S, Brocker EB, LeBoit PE, et al: Distinct sets of genetic alterations in melanoma. N Engl J Med 2005, 353:2135-2147.

4. Van Raamsdonk CD, Bezrookove V, Green G, Bauer J, Gaugler L, O'Brien JM, Simpson EM, Barsh GS, Bastian BC: Frequent somatic mutations of GNAQ in uveal melanoma and blue naevi. Nature 2009, 457:599-602.

5. Van Raamsdonk CD, Griewank KG, Crosby MB, Garrido MC, Vemula S, Wiesner T, Obenauf AC, Wackernagel W, Green G, Bouvier N, et al: Mutations in GNA11 in uveal melanoma. N Engl J Med 2010, 363:2191-2199.

6. Gray-Schopfer V, Wellbrock C, Marais R: Melanoma biology and new targeted therapy. Nature 2007, 445:851-857. 
7. Solit DB, Garraway LA, Pratilas CA, Sawai A, Getz G, Basso A, Ye Q, Lobo JM, She Y, Osman I, et al: BRAF mutation predicts sensitivity to MEK inhibition. Nature 2006, 439:358-362.

8. Bollag G, Hirth P, Tsai J, Zhang J, Ibrahim PN, Cho H, Spevak W, Zhang C Zhang $Y$, Habets $G$, et al: Clinical efficacy of a RAF inhibitor needs broad target blockade in BRAF-mutant melanoma. Nature 2010, 467:596-599.

9. Sondergaard JN, Nazarian R, Wang Q, Guo D, Hsueh T, Mok S, Sazegar H, Macconaill LE, Barretina JG, Kehoe SM, et al: Differential sensitivity of melanoma cell lines with BRAFV600E mutation to the specific raf inhibitor PLX4032. J Transl Med 2010, 8:39.

10. Joseph EW, Pratilas CA, Poulikakos PI, Tadi M, Wang W, Taylor BS, Halilovic E, Persaud $Y$, Xing F, Viale A, et al: The RAF inhibitor PLX4032 inhibits ERK signaling and tumor cell proliferation in a V600E BRAF-selective manner. Proc Natl Acad Sci U S A 2010 107:14903-14908.

11. Flaherty KT, Puzanov I, Kim KB, Ribas A, McArthur GA, Sosman JA, O'Dwyer PJ, Lee RJ, Grippo JF, Nolop K, Chapman PB: Inhibition of mutated, activated BRAF in metastatic melanoma. N Engl J Med 2010, 363:809-819.

12. Chapman PB, Hauschild A, Robert C, Haanen JB, Ascierto P, Larkin J, Dummer R, Garbe C, Testori A, Maio M, et al: Improved survival with vemurafenib in melanoma with BRAF V600E mutation. N Engl J Med 2011, 364:2507-2516.

13. Sosman JA, Kim KB, Schuchter L, Gonzalez R, Pavlick AC, Weber JS, McArthur GA, Hutson TE, Moschos SJ, Flaherty KT, et al: Survival in BRAF V600mutant advanced melanoma treated with vemurafenib. $N$ Engl J Med 2012, 366:707-714.

14. Lin WM, Baker AC, Beroukhim R, Winckler W, Feng W, Marmion JM, Laine E, Greulich $\mathrm{H}$, Tseng $\mathrm{H}$, Gates $\mathrm{C}$, et al: Modeling genomic diversity and tumor dependency in malignant melanoma. Cancer Res 2008, 68:664-673.

15. Haigis KM, Kendall KR, Wang Y, Cheung A, Haigis MC, Glickman JN, NiwaKawakita M, Sweet-Cordero A, Sebolt-Leopold J, Shannon KM, et al: Differential effects of oncogenic K-Ras and N-Ras on proliferation, differentiation and tumor progression in the colon. Nat Genet 2008, 40:600-608.

16. Pratilas CA, Taylor BS, Ye Q, Viale A, Sander C, Solit DB, Rosen N: (V600E) BRAF is associated with disabled feedback inhibition of RAF-MEK signaling and elevated transcriptional output of the pathway. Proc Natl Acad Sci U S A 2009, 106:4519-4524.

17. Zuidervaart W, van Nieuwpoort F, Stark M, Dijkman R, Packer L, Borgstein AM, Pavey S, van der Velden P, Out C, Jager MJ, et al: Activation of the MAPK pathway is a common event in uveal melanomas although it rarely occurs through mutation of BRAF or RAS. Br J Cancer 2005, 92:2032-2038.

18. Weber A, Hengge UR, Urbanik D, Markwart A, Mirmohammadsaegh A, Reiche MB, Wittekind C, Wiedemann P, Tannapfel A: Absence of mutations of the BRAF gene and constitutive activation of extracellular-regulated kinase in malignant melanomas of the uvea. Lab Investig 2003, 83:1771-1776.

19. Dong Q, Dougan DR, Gong X, Halkowycz P, Jin B, Kanouni T, O'Connell SM, Scorah N, Shi L, Wallace MB, Zhou F: Discovery of TAK-733, a potent and selective MEK allosteric site inhibitor for the treatment of cancer. Bioorg Med Chem Lett 2011, 21:1315-1319.

20. O' Connell S, Tsuchiya S, Shi L, Fabrey R, Zhang L, Dong Q, Hori A, Vincent $P$ : BRAF is not the only predictor of sensitivity in vitro and in vivo for TAK-733, a selective potent inhibitor of MEK1/2. Proc Am Assoc Canc Res 2010: Abstract \#2523

21. Emery CM, Vijayendran KG, Zipser MC, Sawyer AM, Niu L, Kim JJ, Hatton C, Chopra R, Oberholzer PA, Karpova MB, et al: MEK1 mutations confer resistance to MEK and B-RAF inhibition. Proc Natl Acad Sci U S A 2009, 106:20411-20416.

22. Atefi M, von Euw E, Attar N, Ng C, Chu C, Guo D, Nazarian R, Chmielowski B, Glaspy JA, Comin-Anduix B, et al: Reversing melanoma cross-resistance to BRAF and MEK inhibitors by co-targeting the AKT/mTOR pathway. PLOS One 2011, 6:e28973.

23. Prahallad A, Sun C, Huang S, Di Nicolantonio F, Salazar R, Zecchin D, Beijersbergen RL, Bardelli A, Bernards R: Unresponsiveness of colon cancer to BRAF(V600E) inhibition through feedback activation of EGFR. Nature 2012, 483:100-103

24. Shi H, Kong X, Ribas A, Lo RS: Combinatorial Treatments That Overcome PDGFR\{beta\}-Driven Resistance of Melanoma Cells to V600EB-RAF Inhibition. Cancer Res 2011, 71:5067-5074.

25. Kirkwood JM, Bastholt L, Robert C, Sosman J, Larkin J, Hersey P, Middleton M, Cantarini M, Zazulina V, Kemsley K, Dummer R: Phase II, open-label, randomized trial of the MEK1/2 inhibitor selumetinib as monotherapy versus temozolomide in patients with advanced melanoma. Clinical cancer research : an official journal of the American Association for Cancer Research 2012, 18:555-567.

26. Infante JR, Fecher LA, Nallapareddy S, Gordon MS, Flaherty KT, Cox DS, DeMarini DJ, Morris SR, Burris HA, Messersmith WA: Safety and efficacy results from the first-in-human study of the oral MEK $1 / 2$ inhibitor GSK1120212. Journal of Clinical Oncology 2010, 28: Abstract 2503.

27. Kefford R, Arkenau H, Brown MP, Millward M, Infante JR, Long GV, Ouellet D, Curtis M, Lebowitz PF, Falchokk GS: Phase I/II study of GSK2118436, a selective inhibitor of oncogenic mutant BRAF kinase, in patients with metastatic melanoma and other solid tumors. J Clin Oncol 2010, 28:611s.

28. Hall-Jackson CA, Eyers PA, Cohen P, Goedert M, Boyle FT, Hewitt N, Plant H, Hedge P: Paradoxical activation of Raf by a novel Raf inhibitor. Chem Biol 1999, 6:559-568.

29. Su F, Viros A, Milagre C, Trunzer K, Bollag G, Spleiss O, Reis-Filho JS, Kong X, Koya RC, Flaherty KT, et al: RAS mutations in cutaneous squamous-cell carcinomas in patients treated with BRAF inhibitors. N Engl J Med 2012, 366:207-215.

30. MacConaill LE, Campbell CD, Kehoe SM, Bass AJ, Hatton C, Niu L, Davis M, Yao K, Hanna M, Mondal C, et al: Profiling critical cancer gene mutations in clinical tumor samples. PLoS One 2009, 4:e7887.

31. Guo D, Hildebrandt IJ, Prins RM, Soto H, Mazzotta MM, Dang J, Czernin J, Shyy JY, Watson AD, Phelps M, et al: The AMPK agonist AICAR inhibits the growth of EGFRvlll-expressing glioblastomas by inhibiting lipogenesis. Proc Natl Acad Sci U S A 2009, 106:12932-12937.

doi:10.1186/1476-4598-11-22

Cite this article as: Euw et al:: Antitumor effects of the investigational selective MEK inhibitor TAK733 against cutaneous and uveal melanoma cell lines. Molecular Cancer 2012 11:22

\section{Submit your next manuscript to BioMed Central and take full advantage of:}

- Convenient online submission

- Thorough peer review

- No space constraints or color figure charges

- Immediate publication on acceptance

- Inclusion in PubMed, CAS, Scopus and Google Scholar

- Research which is freely available for redistribution 